\title{
Implementation of Strategy Based Innovative Teaching and Learning Schemes for Engineering Students
}

\author{
Ravishankar Desai ${ }^{1}$, ShreyasDeshpande ${ }^{2}$ \\ ${ }^{1}$ Instrumentation Engineering, PVPIT, Budhgaon - 416304. \\ ${ }^{2}$ Instrumentation and Control Engineering, PREC, Loni - 413736. \\ ${ }^{1}$ ravishankardesai@gmail.com \\ ${ }^{2}$ shreyas.deshpande19@gmail.com
}

\begin{abstract}
In this paper, innovative teaching andlearning (ITL) schemes for engineering students is beingimplemented on the root of curiosity, observation,intellectual and decide-focus-act strategy. The scheme isdivided into three parts. In first part evaluation schemeare implemented on personality and behaviour,conceptual motivation, process of selfevaluation, beforeyou assess yourself, assessment skill, plan-act-improveaudit,get engaged in value addition drive. In secondpart the students are evaluated by 30\%-70\% schemeand it is implemented on empirical approach,observations, questions, hypotheses, experiments, analyses, conclusions, replications. The third scheme isskill enhancement i.e. assessment scheme and it depend on part first and part second. The above strategy and schemes areimplemented on 50 engineering students and its resultsare tabulated. It is ascertained that, this scheme andstrategy is working excellently.
\end{abstract}

Keywords: Innovative teaching and learning (ITL),innovative teaching and learning (ITL) strategy,innovative teaching and learning(ITL) scheme, strategyand scheme.

\footnotetext{
Ravishankar Desai

Department of Instrumentation Engineering

PadmabhooshanVasantraodadaPatilInstituteof

Technology, Budhgaon, Sangli - 416304. Maharashtra

(INDIA).

ravishankardesai@gmail.com
}

\section{Introduction}

The evaluation of teaching and learning is defined as "a systematic attempt to determine the effects of an educational initiative, innovation or experiment on student learning". Using this definition, the success of a teaching innovation will be determined principally by evidence of changes or improvement of some kind in student learning (Richard J.). A template for innovation or ideation exercises that integrates thinking from the entrepreneurial cognition literature with practical course design elements to systematically develop individual's ideation capabilities (Kevin et al. 2014). For enhancing the learning methodolo-gy used for inductive teaching (includes inquiry, problem based, project-based and discovery, casebased and just-in time) method, highlights commonalities and specific differences, and reviews research on the effectiveness of the methods (Michel and Richard, 2006). In (Khe and Thomas, 2007) identify several current knowledge gaps pertaining to the barriers and strategies of technology integration and offer pertinent recommendations for future research are demonstrated. The major model of design pedagogy, project-based learning and recommended that available research suggests that, these kinds of courses appear to improve retention, student satisfaction, diversity, and student learning (Clive et al. 2005). To introduce innovative in teaching and learning (Tedman and Jain 2000) represents a valid image of the nature of the interaction between science, technology and society. Each field is challengeable and sensible in the arena of engineering education, to attract many students and nurturing welltrained engineers. To fulfill these ways student need to think differently.

The paper is organized as follow. In section 2 ITL strategies is presented, and section 3 represents ITL scheme. The result of ITL strategy and scheme is reported in section 4. Finally, conclusion is drawn in section

\section{Innovative Teaching and Learning (ITL) Strategy}


It allocated into four parts. The following picture stimulateyou for how curious, how to observe, how to build intellectual and how to execute the strategy.

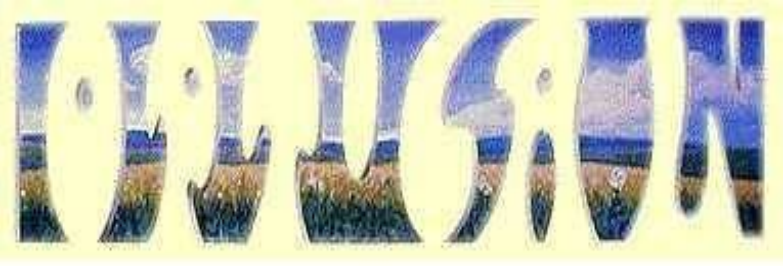

Fig. 1 Strategy to stimulate for implementation

A. Curiosity

A state in which you want to learn more about somethingmeans cognitive state from nature, survey, publiccommunication and how motivating our self. A highlymind storming human activity used in the investigation ofnature and matter that deals specifically with the manner inwhich data is collected analyzed and interpreted.

\section{B. Observation}

An important component in any scientific investigation isobservation. In this sense, observation refers to two distinctconcepts: being aware of the world around us and makingcareful measurements.

\section{Intellectual}

The scientific method can be described as a sequence ofsteps for systematically analyzing scientific questions;designing and executing innovative ideas, answers to thosequestions, and producing reproducible results. The methodadds new knowledge and discoveries to the various realmsand endeavors of the sciences.

\section{Decide-Focus-Act}

This one is the highly dominant strategy because, curiosity,observation, intellectual strategy is applicable forinnovative idea and this one is reflective realism. Whatdecided i.e. innovative idea that will finalized, focusparticularly on respective innovative idea and finally actaccordingly to implement for application.

\section{Innovative Teaching and Learning (ITL) Scheme}

The scheme is divided into evaluation scheme, 30\%-70\% scheme, and assessment scheme. The Newtonian observation that apples fall from trees stimulated much innovation into the effects of gravity. Therefore, a keen eye to your surroundings can often provide you with many ideas for innovative studies.

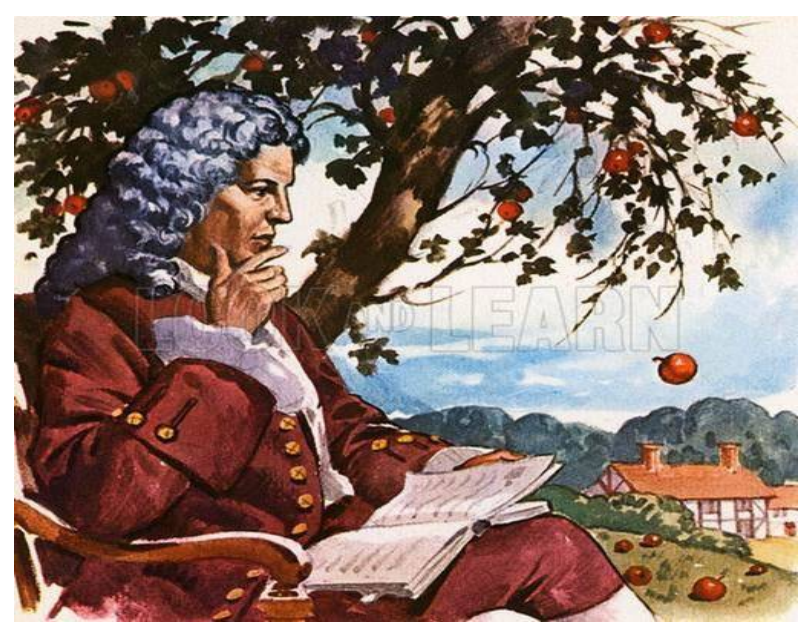

Fig. 2 Scheme to stimulate for implementation

A. Evaluation

This scheme it comes under non-technical part. This can beimplemented as follow:

1) Personality and behaviour:

- Our physical personality and behaviour are themost visible parts.

- Behaviour, basically in the form of verbal andnonverbal communication, is the projective part ofour personality.

- These are the main component of our behaviour:Our attitude and motive, the content, the process(i.e. why, what and how, how of our behaviour.)

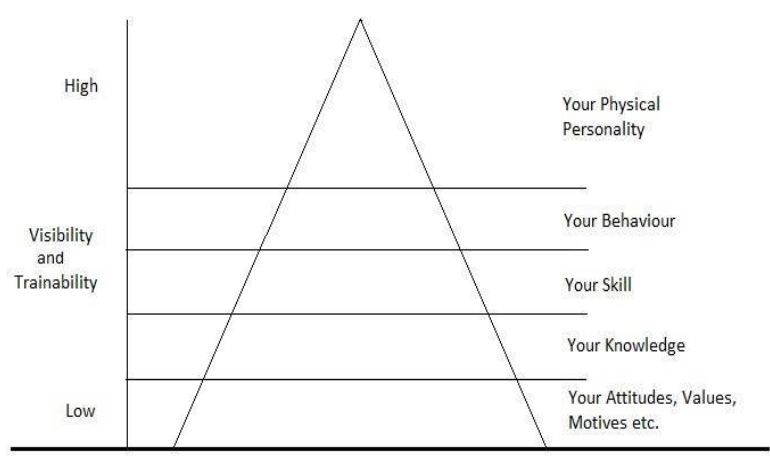

Fig. 3 Layer of personality

\section{2)Conceptual motivation:}

- To err is human. But, if the eraser gets consumedfully before the lead, it is a signal that the mistakescommitted are a bit too many. 


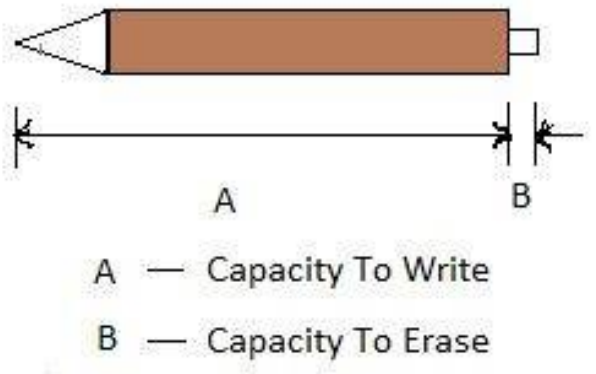

Fig. 4 Concept behind pencil and eraser

3) Process of self-evaluation:

- If you make the behaviour all the time, most of thetime, sometimes, rarely and never.

- The assessment is done yourself and friend.Considering following points.

- I logically breakdown the issue

- I identify various elements

- I collect relevant information and data.

4) Before you assess yourself:

- You think one or two critical situations requiringuse of the skill in question.

- Consider what you did with reference to what youshould have done.

- Do not get into justification of your actions.

- Be aware of the gap between the 'actual and thestandard.

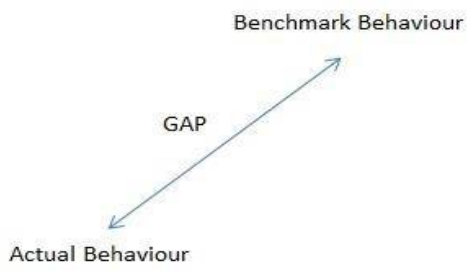

Fig. 5 Awareness of your behavior

5)Assessment skill:

- This task contains different situation and how this situation to be tackles or solve.

- It enhance analysis and creativity for problemsolving, verbal and written communication,presentation, planning activities, team leadershipand membership, initiative, selfconfidence, achievement orientation, learning, and self -management.

6) Plan-act-improve-audit:

- After assessment identify your strengths and the behaviours need for improvements.

- Then follow the steps given below :

- Plan - Plan to change.

- Act - Act as per your planning.
- Improve - Get the result of your action.

- Audit - This is reflective monitoring process.

- Take some time to think and objectively audit the action and the result.

\section{7) Get engaged in value addition drive:}

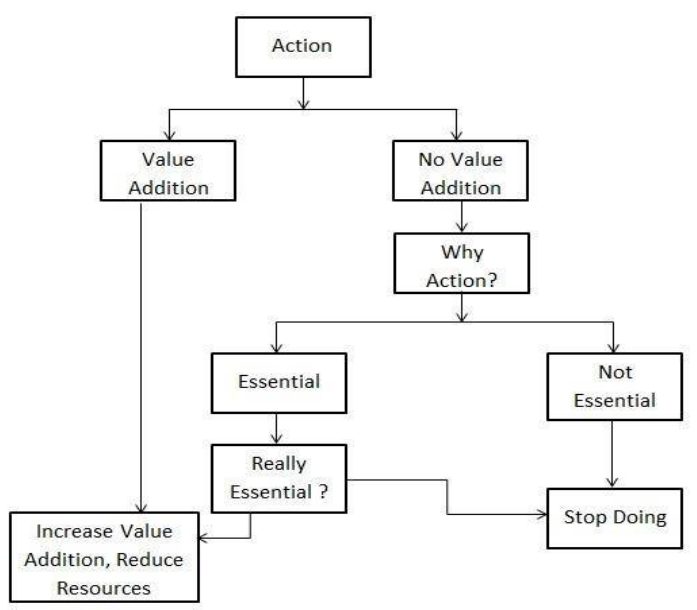

Fig. 6 Model of value addition

- We need to spend resources in the form of time,energy, money etc. The activity may add value ormay not add any value.

- Refer the model of value addition. Reflect on theaction points.

- Can we eliminate or reduce, to the extent possible,non-value adding activities from our life?

- Can we increase the ratio of value addition andresources used?

\section{B. $30 \%-70 \%$}

This scheme it comes under technical part. In secondscheme the students are evaluated by 30\%-70\% scheme. The $30 \%$ is depend on class room programme, it includeshistory (i.e. interlinks, references, importance), conceptwise information (using teaching tools i.e. black board,presentation, animated video), discussion (student tostudent discussion), and question-answer (clarification). The $70 \%$ is depends on laboratory programme, it includesdemonstration, design, implementation, real timeobservation, result, analysis and conclusion. This can beimplemented (Singh Y. K. 2006) as follow:

\section{1) Empirical approach:}

- The empirical approach is an evidencebasedapproach that relies on direct observation andexperimentation in the acquisition of newknowledge along with scientific decisions 
aremade based on the data derived from directobservation and experimentation.

- Additionally, we may often reach conclusions ormake decisions that are not necessarily based ondata, but rather on opinions, speculation, and ahope for the best.

- The empirical approach, with its emphasis ondirect, systematic, and careful observation, is bestthought of as the guiding principle behind allinnovation conducted in accordance with thescientific method.

\section{2) Observations:}

- Observations of the world around us often giverise to the questions that are addressed throughscientific innovation.

- Contrast this approach to decision making with theway that most nonscientific decisions are made inour daily lives.

\section{3) Questions:}

- Many right questions can sort many things.

- It gives direction to start the innovative idea inright way.

4) Hypotheses:

- It is a tentative solution of a problem.

- It is part of innovative activities are planned forverification.

- It is very essential to formulate innovative ideasfor innovator.

\section{5) Experiments:}

- It is hands on experience will encourage us forrealism.

- Only experimental result provides conclusiveevidence regarding cause-and-effect relationships.

\section{6) Analysis:}

- An investigation of the component parts of awhole and their relations in making up the whole.

- The abstract separation of a whole into itsconstituent parts in order to study the parts andtheir relations.

- Analysis is based on available basic data and newdata.

- It is a technique and it has philosophical touch.

\section{7) Conclusions:}

- It comes under main findings, inferences,implication of the findings, limitations andsuggestions for further studies.

- In the form of corrective measures for improvingthe current practices.

- It based on the concept of probability.
- It can be made easily with certain level ofaccuracy.

- For an accurate conclusion it is essential that allvariables except experimental variable should becontrolled.

- The results also concern only to the conditions.

8) Replications:

- It is sensible when an innovation has provided thebasis of some current belief, that the findings stillhold true.

- A treatment is repeated a number of times in orderto obtain a more reliable estimate than is possiblefrom a single observation.

- It provides an estimate of the error to whichcomparisons are subjected.

- It reduces the experimental error.

- It broadens the scope of experiment.

\section{Assessment}

This scheme, it comes under skill development,implementation and presentation. This can be implementedas follow:

\section{1) Seminar}

- It is an exchange of idea.

- It is a way of passing the information aboutrespective topic.

- It is an essential platform where we shareinformation.

- It includes questions, discussions, guidance, andencouragement of topics.

2) Workshop:

- It gives information about design tool used forinnovative idea.

- It is a platform of where demonstrate the designtool.

- It is a portable industry where provide the hands on experience on design tool.

\section{3) Conference:}

- A prearranged meeting among participantsespecially one with a formal agenda.

- It is a place where we exchange information in theform of presentation, poster, animated videos etc.

\section{4) Industrial visit}

- It provides the awareness about realism.

- It gives information about working environment,function, practical aspects.

- It is a way of real and application based teaching.

- It is most effective way of teaching and learning.

\section{5) Apprenticeship programme}


- It is a real time small work in industrialenvironment; through provide awareness aboutinnovation into realism.

- It is an initial stage of working in an industrialenvironment.

- It is boundary of relative and respective workingfield.

- It is a route of successful engineering.

\section{6) Project Exhibition}

- It is an implementation of idea into realism.

- It is a museum where we set-up, develop, anddeliver theoretical and practical knowledge.

- It is an interaction among people.

- It creates enthusiasm and stimulates to dosomething different that one is useful to us.

\section{Result of ITL Strategy and Scheme}

The above strategy and schemes are implemented on 50engineering students and their feedback of each month istabulated based on average of individual students.

Table 1 shows student response on ITL strategy. Fig. 7represents the month-wise chart layout and Fig. 8represents overall performance of student response on ITLstrategy. From Table 1, the decide-focus-act strategy has major variationas compare with other strategy because in stressful situationstudent are not able to face the problems (exam period) and reason is that, pick period of curriculum. But, they are not distracting theircuriosity, observation, and intellectual strategy accepts littlebit variation.

Table 1. Performance of Students Feedback on ITL Strategy

\begin{tabular}{|l|l|l|l|l|}
\hline $\begin{array}{l}\text { ITL } \\
\text { Strategy }\end{array}$ & $\begin{array}{l}\text { First } \\
\text { Month }\end{array}$ & $\begin{array}{l}\text { Second } \\
\text { Month }\end{array}$ & $\begin{array}{l}\text { Third } \\
\text { Month }\end{array}$ & $\begin{array}{l}\text { Overall } \\
\text { Performance }\end{array}$ \\
\hline Curiosity & 94 & 91 & 97.96 & 96 \\
\hline Observation & 97 & 98 & 95 & 96.66 \\
\hline Intellectual & 89 & 93 & 94 & 92 \\
\hline Decide-Focus-Act & 87 & 90 & 96 & 91 \\
\hline Average & $\mathbf{9 1 . 7 5}$ & $\mathbf{9 3}$ & $\mathbf{9 5 . 5}$ & $\mathbf{9 3 . 1 7 5}$ \\
\hline
\end{tabular}

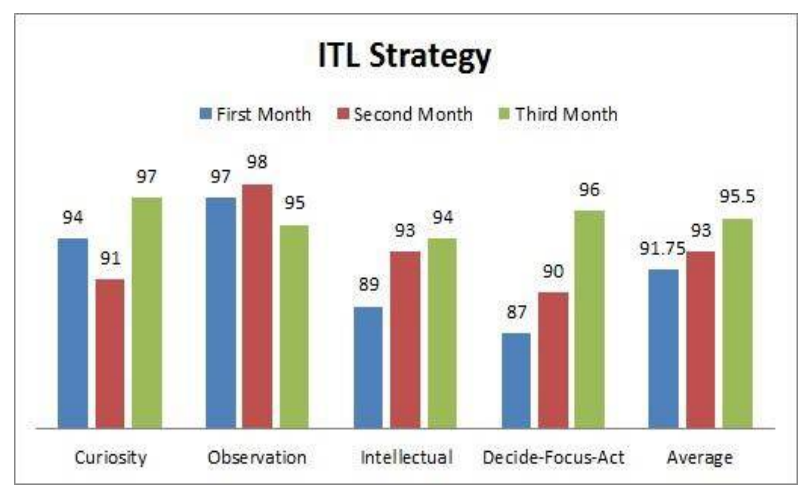

Fig. 7 Month-wise chart layout

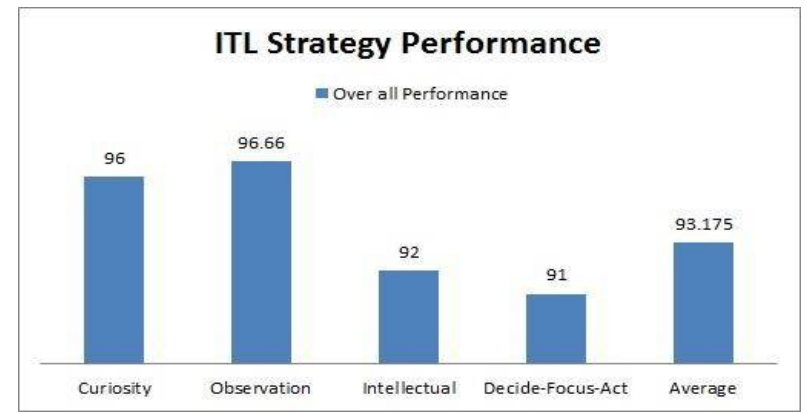

Fig. 8 Chart layout of overall performance

Table 2 shows student response on ITL scheme. Fig. 9 represents the month-wise chart layout and Fig. 10 represents overall performance of student response on ITL scheme. The assessment scheme creates stepwise stress as curriculum is going on. But, it effects on evaluation scheme and $30 \%-70 \%$ scheme. This scheme is based on regular analysis of individual student. Considering little bit variation this one is the highly stimulating and effective scheme.

Table 2. Performance of Students Feedback on ITL Scheme

\begin{tabular}{|l|l|l|l|l|}
\hline $\begin{array}{l}\text { ITL } \\
\text { Scheme }\end{array}$ & $\begin{array}{l}\text { First } \\
\text { Month }\end{array}$ & $\begin{array}{l}\text { Second } \\
\text { Month }\end{array}$ & $\begin{array}{l}\text { Third } \\
\text { Month }\end{array}$ & $\begin{array}{l}\text { Overall } \\
\text { Performance }\end{array}$ \\
\hline Evaluation & 98 & 95 & 92 & 95 \\
\hline 30\%-70\% & 92 & 91 & 94 & 92.33 \\
\hline Assessment & 88 & 94 & 98 & 93.33 \\
\hline Average & $\mathbf{9 2 . 6 6}$ & $\mathbf{9 3 . 3 3}$ & $\mathbf{9 4 . 6 6}$ & $\mathbf{9 3 . 5 5}$ \\
\hline
\end{tabular}

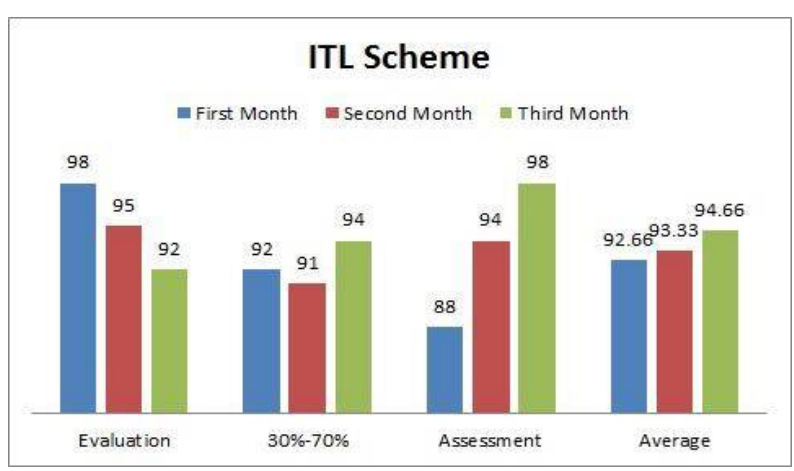

Fig. 9 Month-wise chart layout

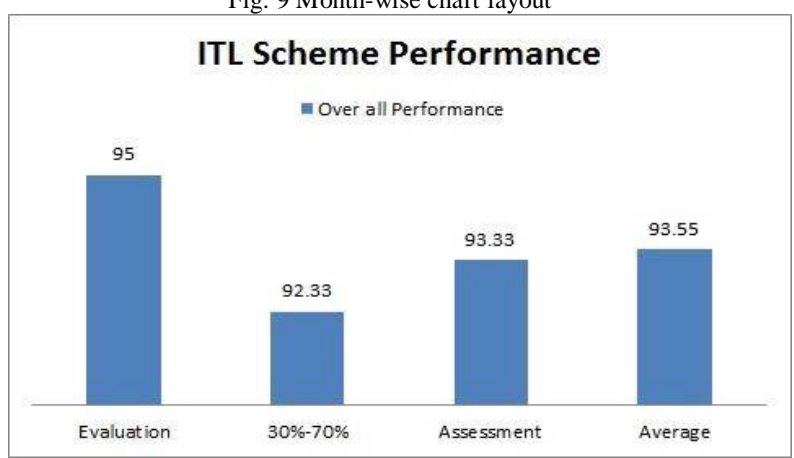

Fig. 10 Chart layout of overall performance 


\section{Conclusions}

In this paper, innovative teaching and learning (ITL) strategy and schemes with their implementation is presented and ithas been implemented on engineering students. The realism of resultsis reported in Section 4 . The response in terms of feedbacks is tabulated separately in Table I, Table II and their chart layouts in Fig. 8 to Fig. 10. The resultshows very good output month-wise along with overallperformance is excellent. We proved that,based on Section 3 information, the implanted method is outcome based with overall emerging methodology of student life.

\section{References}

Richard J., Evaluating Teaching Innovation, Centre for thestudy of higher education.

Kevin C., Bryan B., and Jack S., (2014) ThinkingInnovatively about Teaching Innovation And Ideation:Getting Students to Think Differently, Journal of Researchin Innovative Teaching, CA USA, Volume 7, Issue 1.

Michel P., and Richard F., (2006) Inductive Teaching andLearning Methods: Definitions, Comparisons, and ResearchBases, Journal of Engineering Education.

Michel P., and Richard F., (2006) The Many Faces ofInductive Teaching and Learning, Journal of CollegeScience Teaching.

Khe F. H. and Thomas B, (2007) doi: 10.1007/s11423006-9022-52013.

Clive D., Alice A., Ozgur E., Daniel F., and Larry L.(2005) Engineering Design Thinking, Teaching, andLearning, Journal of Engineering Education.

Tedman D. and Jain L.C. (2000), An Introduction toInnovative Teaching and Learning doi: 0.1007/978-37908-1868-0.

Singh Y. K. (2006), Fundamental of ResearchMethodology and Statistics, New Age International (P)Ltd., New Delhi. 